\title{
$\mathrm{BCCN} 4$ \\ 4th Brazilian Conference on Composite Materials
}

\section{ELECTROMAGNETIC CHARACTERIZATION OF PSU/CARBON BLACK MULTIFUNCTIONAL COMPOSITES}

\author{
Tiago T. S. Braga ${ }^{(1)}$, Daniel C. Silveira ${ }^{(1)}$, Newton A. S. Gomes ${ }^{(2)}$, Mirabel C. Rezende ${ }^{(2,3)}$ \\ and Edson C. Botelho ${ }^{(1)}$
}

(1) Department of Materials and Technology, São Paulo State University (UNESP), School of Engineering of Guaratinguetá, Brazil

(2) Electronic Warfare Laboratory, Technological Institute of Aeronautics (ITA), Brazil

(3) Institute of Science and Technology, Federal University of São Paulo (UNIFESP), Brazil

https://doi.org/10.21452/bccm4.2018.05.06

\begin{abstract}
Multifunctional composites are materials capable of combining structural properties with other properties, such as electrical or thermal conductivity, electromagnetic shielding capacity, among others. With the exponential increase in the use of electrical and electronic devices, a specific type of environmental pollution, electromagnetic interference (EMI), has arisen due to the spurious radiation emitted by such devices. Thus, this work proposes the development of a multifunctional composite material based on polysulfone (PSU) and carbon black (CB) and its electromagnetic characterization in the X-band frequency, between 8.2 and 12.4 GHz, widely used in communication and navigation system. The composite materials were produced with high-performance engineering thermoplastic polymer PSU, organic solvent Dichloromethane and two varieties of additive CB. The composite was processed through hot compression molding of films prepared from PSU polymer solutions with the dispersion of the $\mathrm{CB}$ additive by means of an ultrasonic tip. The composite processing cycle was obtained through the thermal characterization of the films by differential scanning calorimetry (DSC) and the electromagnetic characterization was conducted with a vector network analyzer (VNA) and rectangular waveguide. With the determination of the scattering parameters (Transmission and Reflection) it was possible to evaluate the interaction of the electromagnetic waves with the composites and quantify the portions of energy reflected, transmitted and absorbed. The composite presented a favorable behavior for electromagnetic shielding, with average reflection values greater than $65 \%$, absorption greater than $21 \%$ and transmission lower than $11 \%$.
\end{abstract}

Keywords: Carbon Black, Electromagnetic Characterization, EMI Shielding, Polysulfone, Scattering Parameters. 


\section{INTRODUCTION}

The extensive development of communications equipment and electronic systems has been increasing electromagnetic pollution to new heights, which can lead to the malfunctioning of several types of systems, such as commercial antennas and electronic scientific instruments. Electromagnetic interference can be understood as the disturbance to electronic equipment due to spurious radiation emitted by other electric circuits [1].

Given the need to protect certain components against such pollution, electromagnetic shielding becomes necessary. The shielding is the reduction or attenuation of the waves to prevent interference. There are three mechanisms that can contribute to the effectiveness of electromagnetic shielding: reflection, absorption and multiple reflection inside the material [24].

A wide variety of materials can be used in electromagnetic shielding, with different properties of electrical conductivity, magnetic permeability and geometries [2]. Polymeric matrices are, generally, materials that doesn't have this property, most polymers are transparent to electromagnetic waves. However, to enjoy its excellent properties, such as low specific mass, low cost and ease of use, the dispersion of particles or fibers materials can be used to promote interaction with the waves [3,5], dissipating them through absorption or reflection, according to the additive and concentration [1].

The multifunctional composite class seeks to join structural functions of composites such as strength, stiffness, fracture toughness and damping to non-structural functions, such as electromagnetic shielding [6]. By joining a high-performance engineering polymer such as polysulfone, which, among other properties, has high hardness, impact strength and high temperature resistance, [7] with the carbon black load, a material widely used in electromagnetic shielding research [8-11], multifunctional composites with great potential may be obtained.

The objective of this work is process and characterize multifunctional polymer matrix composite with the dispersion of carbon black particles and verify its effect as EMI shielding material in frequency range between 8.2 and $12.4 \mathrm{GHz}$, most common in communication and navigation systems.

\section{EXPERIMENTAL}

\subsection{Materials}

The polymer matrix used was the amorphous polymer polysulfone, with a specific mass of $1.24 \mathrm{~g} / \mathrm{cm}^{3}$, tensile strength of $70.3 \mathrm{MPa}$, tensile modulus of $2482 \mathrm{MPa}$, flexural strength of 106.2 MPa, flexural modulus of $2689 \mathrm{MPa}$ and glass transition temperature of $185^{\circ} \mathrm{C}$.

To prepare the polymer solution, the solvent used was the organic solvent Dichloromethane in liquid form with clear appearance and ether characteristic odor, with chemical formula $\mathrm{CH}_{2} \mathrm{Cl}_{2}$, specific mass of $1.34 \mathrm{~g} / \mathrm{cm}^{3}$, molecular weight of $84,9 \mathrm{~g} / \mathrm{mol}$, boiling point of $39.8^{\circ} \mathrm{C}$, solidification point of $-96.7^{\circ} \mathrm{C}$ and flash point of $640.5^{\circ} \mathrm{C}$.

To obtain the composite, carbon black additive in powder form was dispersed into the polymer solution. Materials from two different manufacturers was used, XE2B from Degussa, with $35 \mathrm{~nm}$ average particle size, $1,7-1,9 \mathrm{~g} / \mathrm{cm}^{3}$ density at $20{ }^{\circ} \mathrm{C}$ and $1000 \mathrm{~m}^{2} / \mathrm{g}$ specific surface area, and XC72R from Cabot, with $50 \mathrm{~nm}$ average particle size, 1,7-1,9 g/ $\mathrm{cm}^{3}$ density at $20^{\circ} \mathrm{C}$ and $1000 \mathrm{~m}^{2} / \mathrm{g}$ specific surface area.

\subsection{Film production}

The films were produced through the preparation of polymer solutions of PSU and Dichloromethane, using 10 and $90 \% \mathrm{~m} / \mathrm{m}$ content, respectively. The solutions were prepared in fume hood at room temperature and with constant stirring. 
Then, the CB additive were dispersed in the proportion of $15 \% \mathrm{~m} / \mathrm{m}$ of additive to 85 $\% \mathrm{~m} / \mathrm{m}$ of polymer used in the preparation of the polymer solution, using a Sonic \& Materials VC 750 ultrasonic tip, setup with $20 \%$ of maximum amplitude of the equipment for 5 minutes, intercalating 10 seconds in operation and 5 seconds in standby, to avoid overheating and solvent losses.

The preparation of the film was carried out in an oven with temperature control, for 2 hours at $40{ }^{\circ} \mathrm{C}$, to promote the solvent evaporation.

\subsection{Thermal characterization}

The thermal characterization was performed by means of differential scanning calorimetry, in the dynamic mode, of the polymer films, determining the start, peak and end of melt temperatures $\left(\mathrm{T}_{\mathrm{m}}\right)$. A differential calorimeter model Q20 from TA Instruments was used. Hermetic aluminum sample holder and heating rate of $7.6^{\circ} \mathrm{C} / \mathrm{min}$ were used up to $350{ }^{\circ} \mathrm{C}$, to match the heating rate of the hydraulic press used in the processing, followed by cooling down to $25^{\circ} \mathrm{C}$.

\subsection{Composite processing}

The processing of the composite materials, by means of manual lay-up of PSU films with and without carbon black, was performed in a hydraulic press, model CMV100H-15-X, Monarch series from Carver and steel mold of $70 \mathrm{~mm}$ x $70 \mathrm{~mm}$. Heating was performed up to $190{ }^{\circ} \mathrm{C}$, due to limitations of sealing of the mold used, with 10 minutes of isotherm, followed by cooling down to room temperature. The entire process was performed with applied pressure of $2 \mathrm{MPa}$.

\subsection{Electromagnetic characterization}

The determination of the scattering parameters of the composite samples was performed using a four-port vector network analyzer (VNA) model PNA-L N5230C from Agilent Technologies, using ports 2 and 4, frequency generator between $300 \mathrm{kHz}$ and $20 \mathrm{GHz}$, rectangular waveguide with adapter model 00281-60016 OPTION 006 also from Agilent Technologies. The transmitted and reflected energy plots were calculated using equation 1 [12].

$$
\text { Attenuation }(\%)=100 \cdot\left[1-10\left(\frac{-d B}{10}\right)\right]
$$

From the calculation of the transmitted and reflected energy portions it is possible to determine the percentage of energy absorbed by the composite through equation 2 [13].

$$
\text { Absorption }(\%)=100-(\text { Reflection }+ \text { Transmission })
$$

\section{RESULTS AND DISCUSSION}

\subsection{Thermal characterization and processing cycle}

From the DSC of the PSU films, the temperature range at which the material melts was determined. Figure 1 presents the melting heat flow vs temperature graph. 


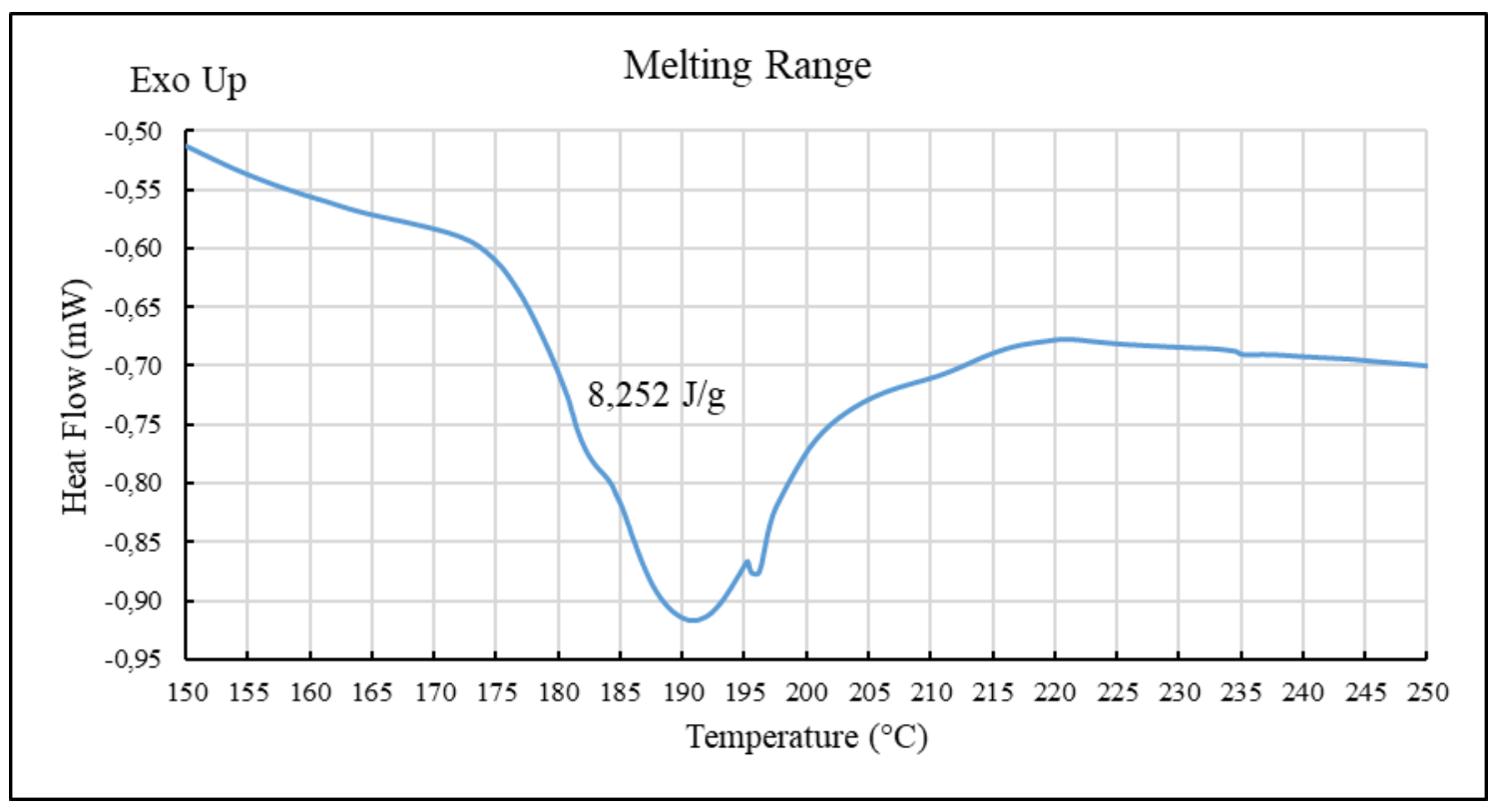

Figure 1: Melting range.

Based on the DSC characterization, the hot compression molding cycle was designed. Figure 2 presents the processing cycle, with constant applied pressure of $2 \mathrm{MPa}$.

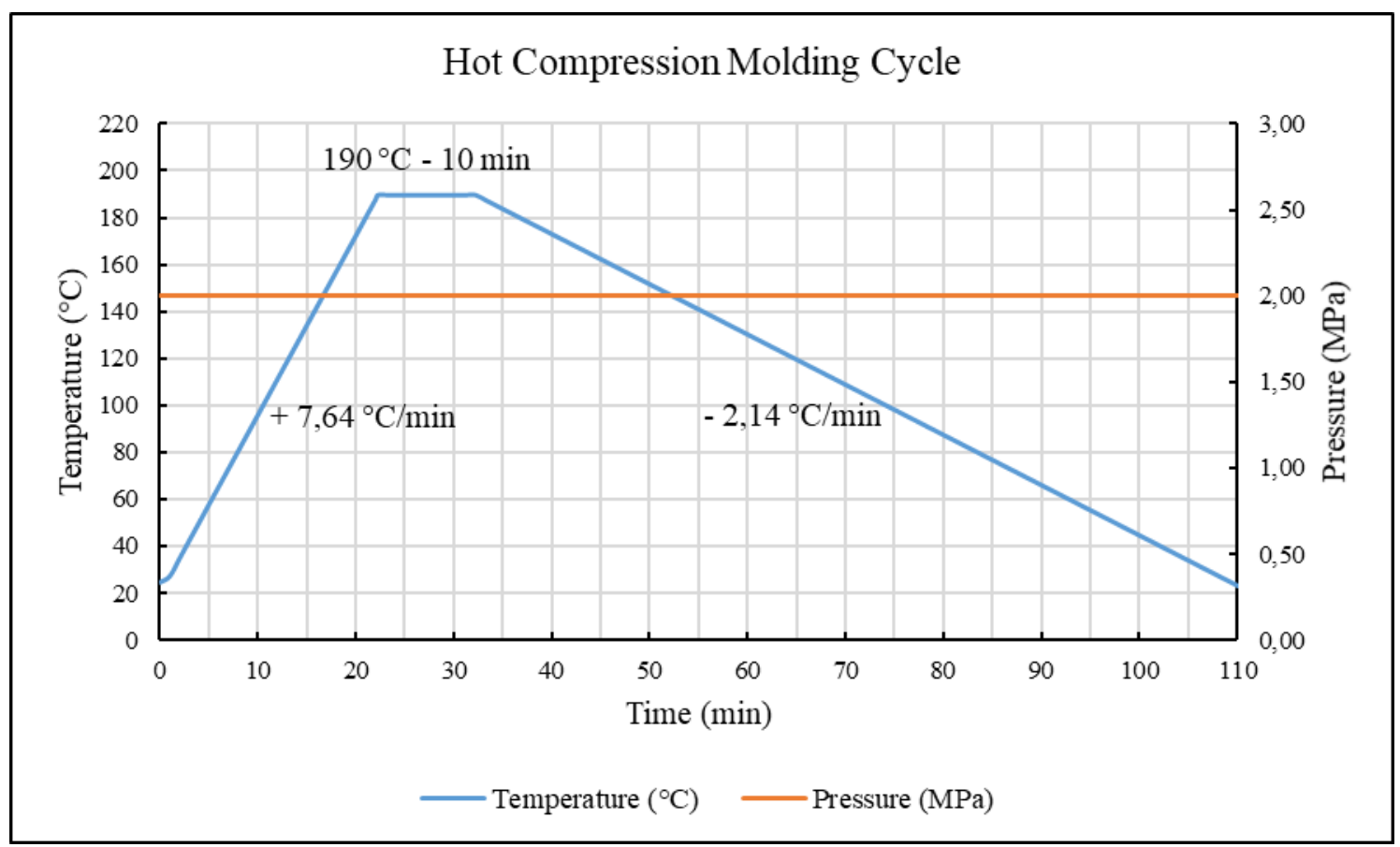

Figure 2: Hot compression molding cycle.

Through the thermal analyzes and the processing of the films, a composite in the form of a plate with $70 \mathrm{~mm} \times 70 \mathrm{~mm}$ dimensions and thickness between 1.1 and $1.3 \mathrm{~mm}$ was obtained. From the qualitative evaluation of the plaques obtained, as union of the layers and rigidity of the plate, the parameters used were considered adequate to proceed to the electromagnetic characterization of the composite samples. 


\subsection{Electromagnetic characterization}

The electromagnetic characterization of the materials provided the scattering parameters for each sample: PSU films and composites, $85 \% \mathrm{~m} / \mathrm{m}$ PSU $+15 \% \mathrm{~m} / \mathrm{m}$ Degussa CB and 85 $\% \mathrm{~m} / \mathrm{m}$ PSU $+15 \% \mathrm{~m} / \mathrm{m}$ Cabot CB.

With the attenuation data regarding transmission and reflection in the composite, and with equations 1 and 2, it is possible to generate graphs relating the transmission, reflection and absorption at each frequency in the studied range.

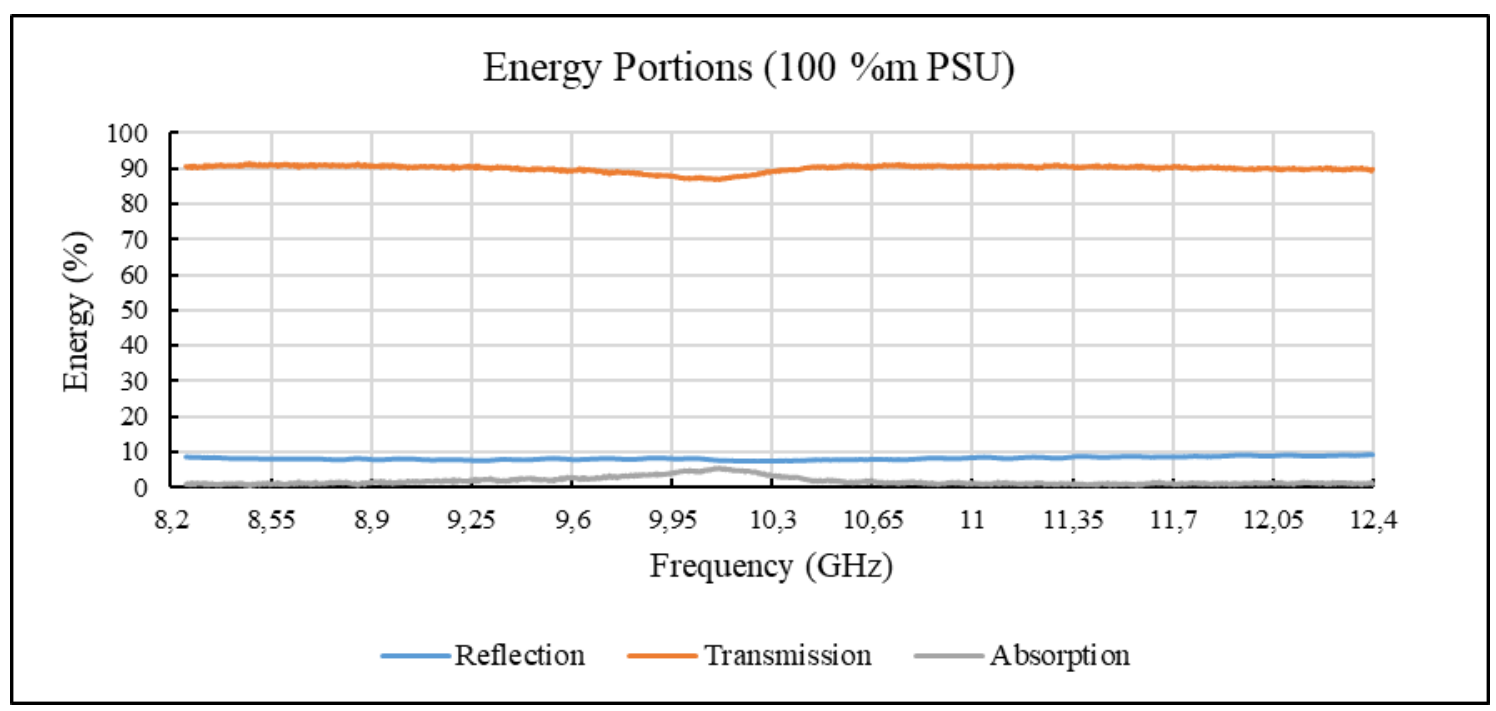

Figure 3: Energy portions (100 \%m PSU).

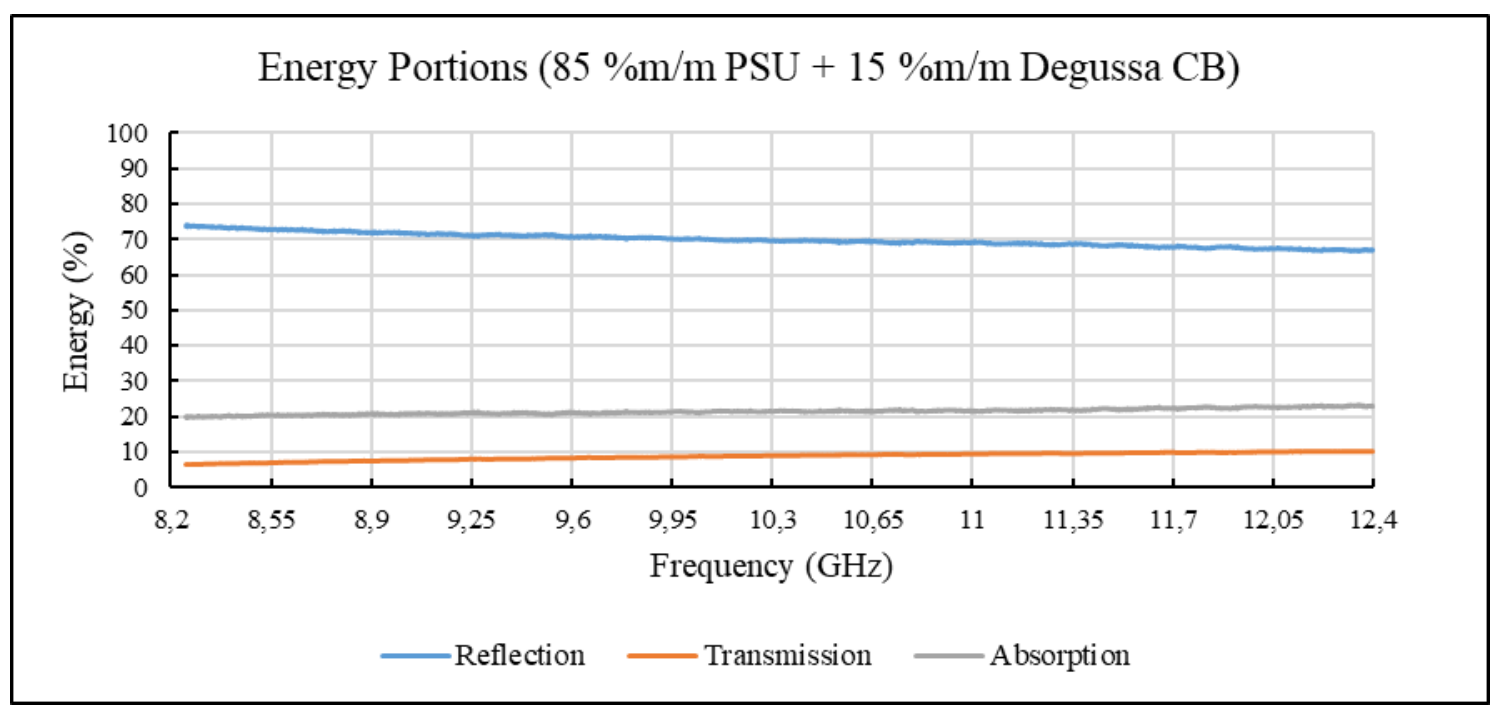

Figure 4: Energy portions (85 \%m/m PSU + $15 \% \mathrm{~m} / \mathrm{m}$ Degussa CB). 


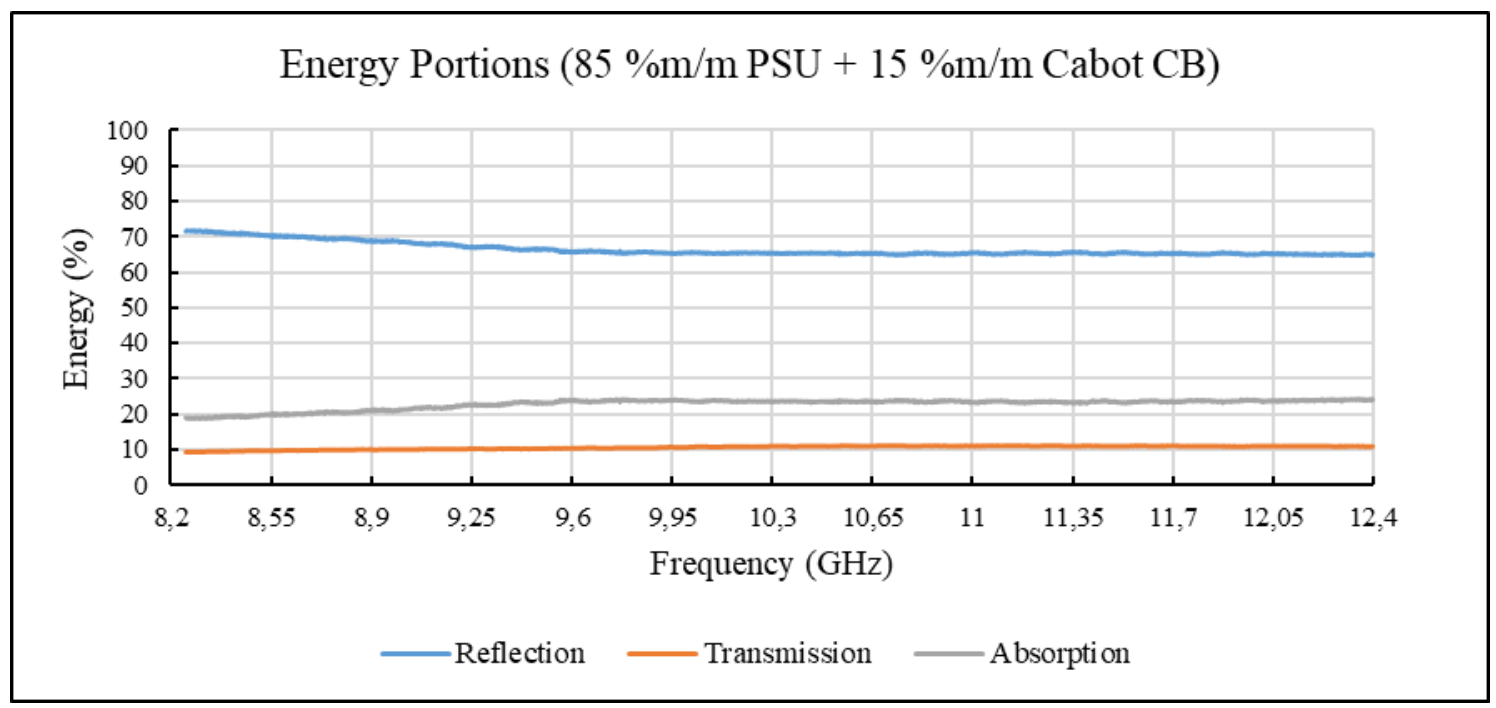

Figure 5: Energy portions (85 \%m/m PSU + $15 \% \mathrm{~m} / \mathrm{m}$ Cabot CB).

It is observed that in all cases the transmitted, reflected and absorbed energy portions remained practically constant throughout the studied frequency range.

From the analysis of the graphs it is possible to obtain the average values of each energy portion for each sample, as shown in table 1.

Table 1: Mean values of energy portions for each sample.

\begin{tabular}{|c|c|c|c|}
\hline Sample & $\begin{array}{c}\text { Transmitted Energy } \\
(\%)\end{array}$ & $\begin{array}{c}\text { Reflected Energy } \\
(\%)\end{array}$ & $\begin{array}{c}\text { Absorbed Energy } \\
(\%)\end{array}$ \\
\hline $100 \% \mathrm{~m}$ PSU & 89,94 & 8,26 & 1,80 \\
\hline $\begin{array}{c}85 \% \mathrm{~m} / \mathrm{m} \text { PSU + } \\
15 \% \mathrm{~m} / \mathrm{m} \text { Degussa CB }\end{array}$ & 8,68 & 69,95 & 21,37 \\
\hline $\begin{array}{c}85 \% \mathrm{~m} / \mathrm{m} \text { PSU + } \\
15 \% \mathrm{~m} / \mathrm{m} \text { Cabot CB }\end{array}$ & 10,70 & 66,52 & 22,78 \\
\hline
\end{tabular}

Despite the dimensional difference between the two varieties of CB used, the results obtained showed similar behavior, however the Degussa sample shows slightly higher reflection while the Cabot sample shows slightly higher transmission and absorption of the electromagnetic energy.

Therefore, it is observed that the composites present main behavior of high reflection, low transmission and intermediate absorption, characterizing their potential use for electromagnetic shielding.

\section{CONCLUSIONS}

Multifunctional composites based on polysulfone and carbon black were produced by hot compression molding of films prepared from the dissolution of the polymer with dichloromethane, followed by the dispersion via ultrasonic tip of carbon black additives.

Through the thermal characterization of the films by differential scanning calorimetry, it was possible to determine the start, peak and final melting temperatures of the polymer, which 
along with information obtained from the literature, provided the designed hot compression molding cycle.

With the electromagnetic characterization, through a vector network analyzer and rectangular waveguide, it was possible to measure the scattering parameters of the composite when it was affected by electromagnetic waves in the X-band, between 8.2 and $12.4 \mathrm{GHz}$.

The composite material presents potential for EMI shielding, exhibiting highly reflective behavior, combined with intermediate absorption of microwaves. Promoting the shielding to approximately $90 \%$ of the electromagnetic radiation in all amplitude analyzed.

\section{ACKNOWLEDGEMENTS}

The authors are grateful to CNPq, São Paulo State University (UNESP) and Electronic Warfare Lab. in Technological Institute of Aeronautics (ITA).

\section{REFERENCES}

[1] Thomassin, J-M., Jérôme, C., Pardoen, T., Bailly, C., Huynen, I., Detrembleur, C., 'Polymer/carbon based composites as electromagnetic interference (EMI) shielding materials', Materials Science and Engineering R 74 (2013) 211-232.

[2] Tong, X.C., 'Advanced Materials and Design for Electromagnetic Interference Shielding', 1st Edn (Boca Raton, Florida, 2008).

[3] Chung D.D.L. 'Electromagnetic interference shielding effectiveness of carbon materials', Carbon 39 (2001) 279-285.

[4] Sudha, J.D., Sivakala, S., Prasanth, R., Reena V.L., Radhakrishnan Nair, P., 'Development of electromagnetic shielding materials from the conductive blends of polyaniline and polyaniline-clay nanocomposite-EVA: Preparation and properties', Composites Science and Technology 69 (2009) 358-364.

[5] Dhawan, S.K., Singh, N., Rodrigues, D., 'Electromagnetic shielding behavior of conducting polyaniline composites', Science and Technology of Advanced Materials 4 (2003) 105-113.

[6] Gibson R.F., 'A review of recent research on mechanics of multifunctional composite materials and structures', Composite Structures 92(12) (2010) 2793-2810.

[7] Ebewele, R.O., 'Polymer science and technology' (Boca Raton, Florida, 1996).

[8] Mondal, S., Ganguly, S., Rahaman, M., Aldalbahi, A., Chaki, T.K., Khastgir, D., Das, N.Ch., 'A strategy to achieve enhanced electromagnetic interference shielding at low concentration with a new generation of conductive carbon black in a chlorinated polyethylene elastomeric matrix’, Physical Chemistry Chemical Physics 18(35) (2016) 24591-24599.

[9] Wen, Y., Song, J., Chen, J., Sun, Y., Yang, W., 'Synergistic Conductivity and Electromagnetic Interference Shielding Effectiveness of Epoxy/Carbon Fiber and Epoxy/Carbon Black Composites via Mixing with Bamboo Charcoal’, BioResources 12(1) (2017) 1288-1299.

[10] Song, J., Yuan, Q. Zhang, H., Huang, B., Fu, F., 'Elevated conductivity and electromagnetic interference shielding effectiveness of PVDF/PETG/carbon fiber composites through incorporating carbon black', Journal of Polymer Research 22 (2015) 158.

[11] Kuester, S., Merlini, C., Barra, G.M.O., Ferreira Jr., J.C., Lucas, A., Souza, A.C., Soares, B.G., 'Processing and characterization of conductive composites based on poly(styrene-b-ethylene-ran-butylene-b-styrene) (SEBS) and carbon additives: A comparative study of expanded graphite and carbon black', Composites Part B 84 (2016) 236-247.

[12] Lee, S.M., 'International encyclopedia of composites', (New York, New York, 1991).

[13] Gupta, K.K., Abbas, S.M., Goswami, T.H., Abhyankar, A.C., 'Microwave absorption in $\mathrm{X}$ and $\mathrm{Ku}$ band frequency of cotton fabric coated with Ni-Zn ferrite and carbon formulation in polyurethane matrix', Journal of Magnetism and Magnetic Materials 362 (2014) 216-225. 